\title{
Ionization Energies, Electron Affinities and Excitation Energies of some Steroid Hormones Calculated with the Semiempirical HAM/3 Method
}

\author{
Yuji Takahata* and Rosana Vendrame
}

\author{
Instituto de Química, Universidade Estadual de Campinas, C. P. 6154, 13083-970, Campinas - SP, Brazil
}

\begin{abstract}
Potenciais de ionização, afinidades eletrônicas e energias de excitação de hormônios sexuais humanos, tais como testosterona, estradiol, além de outros hormônios relacionados foram calculados pelo método semiempírico HAM/3. O espectro fotoeletrônico observado de um esteróide, a androst4-eno-3,17-diona, foi analisado por comparação com as energias de ionização calculadas. Os espectros eletrônicos de excitação na região entre 50 e $350 \mathrm{~nm}$ foram simulados utilizando os valores calculados. Existe uma banda de excitação característica, de alta intensidade, na região entre 75 e $100 \mathrm{~nm}$ em todos os esteróides estudados. Os espectros de transição na região acima de $150 \mathrm{~nm}$ são diferentes de uma molécula para outra.
\end{abstract}

Ionization energies, electron affinities and excitation energies of human sexual hormones such as testosterone, estradiol and related hormones were calculated with the semiempirical HAM/ 3 method. Observed photoelectron spectrum of androst-4-ene-3,17-dione was assigned using the calculated ionization energies. Spectra of electronic excitations in the region between 50 and $350 \mathrm{~nm}$ of the molecules were simulated using the calculated values. There is a characteristic, high intensity, excitation band in the region between $75 \mathrm{~nm}$ and $100 \mathrm{~nm}$ in all of the steroids studied. The transition spectra above $150 \mathrm{~nm}$ region are different from molecule to molecule.

Keywords: steroid, human sexual hormones, excitation spectra, photoelectron spectrum, semiempirical HAM/3 method

\section{Introduction}

The human sexual hormones such as testosterone (male hormone), estradiol (female hormone) and related hormones play fundamental roles in human beings in many aspects. Biological activity of these hormones depends on their geometrical and electronic structure ${ }^{1}$. Therefore, it is desirable to have detailed knowledge of geometrical and electronic structure of these hormones. The human sexual hormones are biologically synthesized in a pathway with many steps starting from cholesterol. The pathway for the biotransformation can be as following: cholestrerol $\rightarrow \cdots \cdots \rightarrow$ dehydroepiandrosterone $(\mathbf{1}) \rightarrow$ androstenedione (2) $\rightarrow$ testosterone (3) $\rightarrow$ estradiol-17 $\beta$ (4). Some of the intermediate steps of the biotransformation have been omitted for the sake of convenience. In the previous study ${ }^{2}$, we calculated ionization energies and electron affinities of $5 \alpha$-androstane and some of its derivatives with the semiempirical HAM/3 method $^{3-4}$. It was shown that good

* e-mail: taka@iqm.unicamp.br agreement between theory and experiment for ionization events that originate from non-bonding orbital of carbonyl oxygen and $\pi$ orbital in $\mathrm{C}=\mathrm{C}$ bonds were found. Excitation energies calculated by the HAM/3 method reproduce observed spectra fairly satisfactory ${ }^{5-10}$. The method is also capable of calculating electron affinity ${ }^{4}, 11$. In the present work, we calculate not only ionization energies and electron affinities of the steroid hormones, 1, 2, 3, 4 and nortestosterone (5) but also calculate their excitation energies. The molecular structures of the five steroid hormones are shown in Figures 2-6. We want to know how the electronic strucure changes as the biotransformation proceeds $\mathbf{1} \rightarrow \mathbf{2} \rightarrow \mathbf{3} \rightarrow \mathbf{4}$ and also what the main differences between the male hormone and the female hormone are in terms of the electronic structure and electronic spectra.

\section{Method of Calculation}

The molecular geometry of the five steroids was optimized with the MM3(92) method on an IBM RISC6000 Model 320 computer. The ionization energies, electron affinities and excitation energies, together with oscillator 
strengths of the five steroid hormones, $\mathbf{1 - 5}$, were calculated with the HAM/3 program. The configuration interaction (CI) method was employed for the calculations of the excitation energies including about 150 singly excited configurations. The HAM/3 program purchased from QCPE $^{12}$ and a SUN workstation SPARC station 1+ was employed for the calculations. Using the calculated ionization energies and oscillator strengths, spectra of the compounds were simulated. A computer program SPECTRUM ${ }^{13}$ was employed to draw the spectra. Gaussian lineshape was assumed. The spectra were generated with $\mathrm{HWHM}$ (Half-Width at Half-Maximum) value of $10 \mathrm{~nm}$ and frequency step size of $1 \mathrm{~nm}$.

\section{Results and Discussion}

The low resolution HeI photoelectron spectrum(PES) of compound $\mathbf{2}$, obtained by Cvitas et al. ${ }^{14}$, is schematically reproduced in the Figure 1. The ionization energies of the compound calculated with HAM/3 are depicted in the top part of the figure. There are two distinct, low energy, low intensity bands in the observed spectrum at $8.90 \mathrm{eV}$ and $9.25 \mathrm{eV}$. The corresponding $\mathrm{HAM} / 3$ values are $8.71 \mathrm{eV}$ $\left(\mathrm{HOMO}-1=\mathrm{n}_{\mathrm{O} 3}\right)$ and $9.21 \mathrm{eV}\left(\mathrm{HOMO}-2=\mathrm{n}_{\mathrm{O} 17}\right)$, respectively. The agreement between theory and experiment is good for these two ionization events. The first highest occupied molecular orbital (HOMO-1) consists mainly of the nonbonding orbital of the carbonyl oxygen at ring position $3\left(\mathrm{n}_{\mathrm{O} 3}\right)$, whereas the second HOMO (HOMO-2) consists mainly the nonbonding orbital of the carbonyl oxygen at ring position $17\left(\mathrm{n}_{\mathrm{O} 17}\right)$. The compound has one carbon-carbon double bond, $\mathrm{C} 4=\mathrm{C} 5$, between positions 4 and 5 , in addition to the two carbonyls, $\mathrm{C} 3=0$ and $\mathrm{C} 17=0$. The third HOMO (HOMO-3) consists mainly of the $\pi$ orbital in $\mathrm{C} 4=\mathrm{C} 5$ bond. The ionization energy that originates from HOMO-3 was calculated to be $9.73 \mathrm{eV}$. The third observed band at $10.17 \mathrm{eV}$ in the PES can be assigned as the ionization event from the $\mathrm{C} 4=\mathrm{C} 5$ bond. The observed bands in the region between $10 \mathrm{eV}$ and 18 $\mathrm{eV}$ are broad and complicated. The values of the calculated ionization energies in this region are located close to each other. The observed broad bands are the consequences of overlap of the narrowly located large number of ionization events. There is no way to assign these broad bands.

The reactivity of a molecule against electrophilic reagents depends mainly on the top few HOMO's according to the frontier-molecular orbital method ${ }^{15}$. The reactivity against an electrophilic reagent decreases in the order: HOMO-

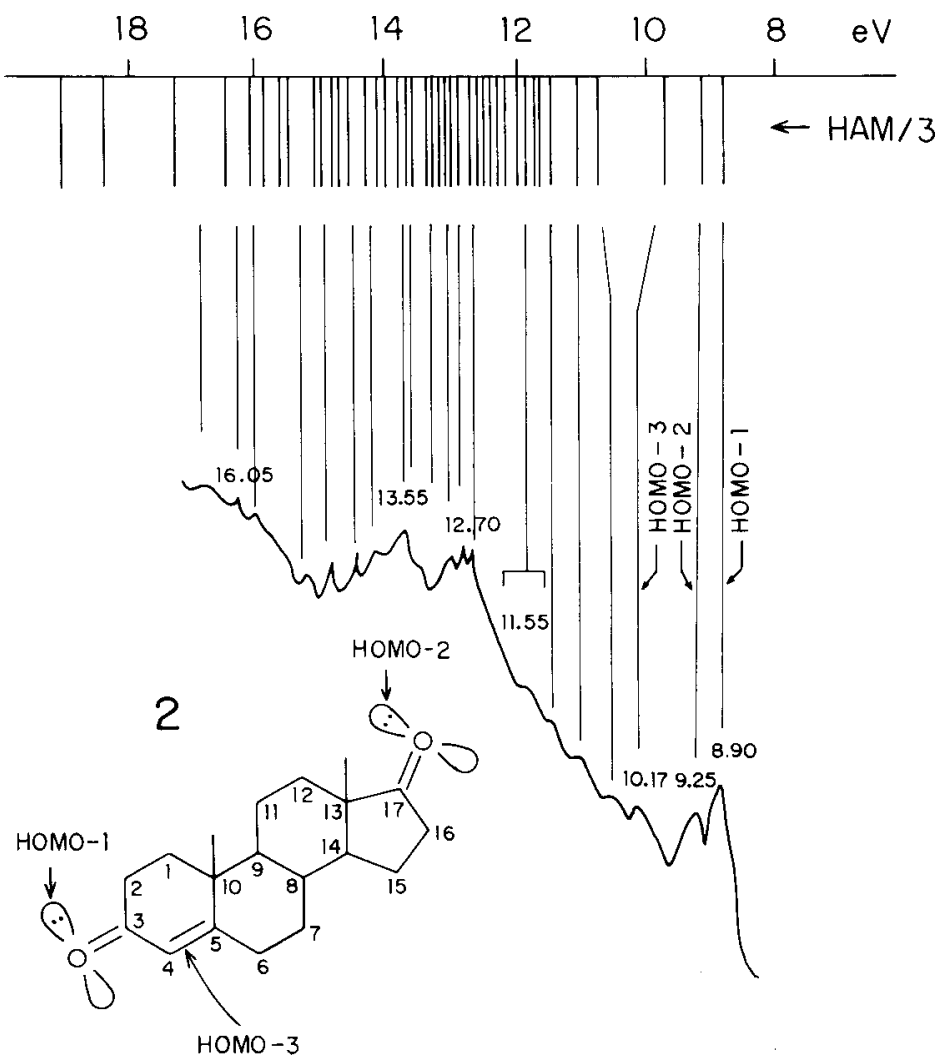

Figure 1. Ionization energies of androst-4-ene-3,17-dione(2) calculated with HAM/3 are shown in the top part of the figure. The low resolution HeI PE spectrum obtained by Cvitas et al. ${ }^{14}$ is reproduced schematically. 
$1>$ HOMO-2>HOMO-3>,... The electrons in HOMO-1 are the most reactive against electrophilic reagents because they are the least bound (the lowest ionization energy) to the molecule. The electrons in the HOMO-2 are the second most reactive because they are the second least bound to the molecule and so on. In case of molecule 2 , the reactivity against electrophilic reagents decreases in the order: $\mathrm{n}_{\mathrm{O} 3}>\mathrm{n}_{\mathrm{O} 17}>$ $\mathrm{C} 4=\mathrm{C} 5$. A positively charged proton in $\mathrm{H}-\mathrm{X}-\mathrm{R}$ can be considered an electrophilic reagent when it establishes a hydrogen bond Y...H-X-R, where X and $\mathrm{Y}$ can be either oxygen or nitrogen atoms. The nonbonding electron pair in $\mathrm{n}_{\mathrm{O} 3}$ should establish stronger hydrogen bond than that in $\mathrm{n}_{\mathrm{O} 17}$ of $\mathbf{2}$. This is in accord with the notion that the A-ring plays an important role in the steroid and the receptor interactions ${ }^{16}$.

Table 1 lists some of the low ionization energies of the five molecules calculated with $\mathrm{HAM} / 3$. In molecule 1 , the first HOMO (HOMO-1) corresponds to the $\pi$-orbital in the carbon-carbon double bond $\mathrm{C} 5=\mathrm{C} 6$, the second HOMO (HOMO-2) corresponds to the nonbonding orbital of the carbonyl oxygen $(\mathrm{C}=\mathrm{O})$ at the position $17, \mathrm{n}_{\mathrm{O} 17}$, and the third HOMO (HOMO-3) corresponds to the nonbonding orbital $\left(\mathrm{n}_{\mathrm{O} 3}\right)$ of the hydroxyl oxygen $(-\mathrm{OH})$ at the position 3 . In the case of testosterone (3), HOMO-1 corresponds to the nonbonding orbital of the 3-keto oxygen $\left(\mathrm{n}_{\mathrm{O} 3}\right)$; HOMO2 is the $\pi$ orbital in the $\mathrm{C} 4=\mathrm{C} 5$ bond; HOMO -3 is the nonbonding orbital of hydroxyl oxygen at $17\left(\mathrm{n}_{\mathrm{O} 17}\right)$. When testosterone interacts with its receptor, the 3-keto oxygen is mainly responsible for interaction with its receptor establishing a hydrogen-bonding network since the HOMO1 in the steroid $\mathbf{3}$ is mainly the nonbonding orbital localised on the 3-keto oxygen ${ }^{16}$. In the case of estradiol (4), HOMO1 is anti bonding combination between the oxygen $\pi$ orbital in the 3-hydroxyl $(-\mathrm{OH})$ and the $\pi$-orbital of the benzene ring (A-ring). HOMO-2 consists mainly of $\pi$-orbital concentrated in the benzene ring with negligible contribution from the 3-hydroxyl oxygen. HOMO-3 is nonbonding orbital, $\mathrm{n}_{\mathrm{O} 17}$, of the oxygen atom in the 17-hydroxyl (-OH) in the D-ring. The crystal structure of the complex formed by 4 and human estrogen receptor- $\alpha$ ligand binding domain (hER $\alpha$ LBD) has been reported by Tanenbaum et al ${ }^{17}$. According to Figure 3 of reference 16, the 3-hydroxyl in the A-ring establishes a hydrogen-bonding network which consists of two hydrogen bonds: one with Glu 353 and one with a water molecule. The $17 \beta$-hydroxyl in the D-ring forms one hydrogen bond with His 524. Since the 3-hydroxyl belongs to HOMO-1 and the $17 \beta$-hydroxyl belongs to the

Table 1. Ionization energies (eV) that originate from top few Highest Occupied Molecular Orbitals (HOMOs) of the five steroids calculated with the HAM/3 method.

\begin{tabular}{|c|c|c|c|}
\hline Steroid & HAM/3 & Type of MOs & Observed $^{a}$ \\
\hline 1 & $\begin{array}{l}9.07 \\
9.19 \\
10.00 \\
10.78 \\
10.94\end{array}$ & $\begin{array}{l}\pi(\mathrm{C} 5=\mathrm{C} 6) ; \mathrm{HOMO}-1 \\
\mathrm{n}_{\mathrm{O}}(\text { in } \mathrm{C} 17=\mathrm{O}) ; \mathrm{HOMO}-2 \\
\mathrm{n}_{\mathrm{O}}(\text { in } \mathrm{C} 3-\mathrm{OH}) ; \mathrm{HOMO}-3 \\
\text { HOMO-4 } \\
\text { HOMO-5 }\end{array}$ & \\
\hline 2 & $\begin{array}{l}8.71 \\
9.21 \\
9.73 \\
10.83 \\
11.17\end{array}$ & $\begin{array}{l}\mathrm{n}_{\mathrm{O}}(\text { in } \mathrm{C} 3=\mathrm{O}) ; \text { HOMO-1 } \\
\mathrm{n}_{\mathrm{O}}(\text { in } \mathrm{C} 17=\mathrm{O}) ; \text { HOMO-2 } \\
\pi(\mathrm{C} 4=\mathrm{C} 5) ; \text { HOMO-3 } \\
\text { HOMO-4 } \\
\text { HOMO-5 }\end{array}$ & $\begin{array}{l}8.90 \\
9.25 \\
10.17\end{array}$ \\
\hline 3 & $\begin{array}{l}8.80 \\
9.74 \\
10.08 \\
10.85 \\
11.05\end{array}$ & $\begin{array}{l}\mathrm{n}_{\mathrm{O}}(\text { in } \mathrm{C} 3=\mathrm{O}) ; \mathrm{HOMO}-1 \\
\pi(\mathrm{C} 4=\mathrm{C} 5) ; \mathrm{HOMO}-2 \\
\mathrm{n}_{\mathrm{O}}(\text { in } \mathrm{C} 17-\mathrm{OH}) ; \mathrm{HOMO}-3 \\
\text { HOMO-4 } \\
\text { HOMO-5 }\end{array}$ & \\
\hline 4 & $\begin{array}{l}8.23 \\
8.87 \\
9.75 \\
10.49 \\
10.53 \\
10.91\end{array}$ & $\begin{array}{l}\pi_{1}\left(\text { benzene } \mathrm{e}_{1} \text { type) }-\pi(\mathrm{OH}) ; \text { HOMO-1 }\right. \\
\pi_{2} \text { (benzene } \mathrm{e}_{1} \text { type); HOMO-2 } \\
\mathrm{n}_{\mathrm{O}}(\text { in C17-OH); HOMO-3 } \\
\text { HOMO-4 } \\
\pi_{3}\left(\text { benzene } \mathrm{a}_{1 \mathrm{~g}} \text { type); HOMO-5 }\right. \\
\text { HOMO-6 }\end{array}$ & \\
\hline 5 & $\begin{array}{l}8.74 \\
9.62 \\
9.90 \\
10.78 \\
11.00\end{array}$ & $\begin{array}{l}\mathrm{n}_{\mathrm{O}}(\text { in } \mathrm{C} 3=\mathrm{O}) ; \mathrm{HOMO}-1 \\
\pi(\mathrm{C} 4=\mathrm{C} 5) ; \mathrm{HOMO}-2 \\
\left.\mathrm{n}_{\mathrm{O}} \text { (in } \mathrm{C} 17-\mathrm{OH}\right) ; \mathrm{HOMO}-3 \\
\text { HOMO-4 } \\
\text { HOMO-5 }\end{array}$ & \\
\hline
\end{tabular}


HOMO-3, we can expect that 3-hydroxyl can form stronger hydrogen bonds than that of the 17 $\beta$-hydroxyl. It has been estimated $^{18}$ that the 3 -hydroxy contributes about $1.9 \mathrm{kcal}$ $\mathrm{mol}^{-1}[1 \mathrm{cal}=4.18 \mathrm{~J}]$ to the binding free energy and $17 \beta$ hydroxyl contributes approximately $0.6 \mathrm{kcal} \mathrm{mol}^{-1}$. The binding between 3-hydroxyl and its receptor is about three times greater than that between $17 \beta$-hydroxyl and its receptor. This estimation and the observed fact that the 3hydroxyl forms two hydrogen bonds while the $17 \beta$-hydroxyl forms only one hydrogen bond can be attributed to the difference in the capability of forming hydrogen bond between HOMO-1 and HOMO-3.
Table 2 lists calculated electron affinities of the five steroids. Among the electron affinities that originate from the first lowest unoccupied molecular orbital (LUMO-1) of the five compounds, the female hormone $\mathbf{4}$ has the smallest electron affinity, while the male hormone $\mathbf{3}$ has the greatest electron affinity of the five steroids studied. LUMO energy is closely related to reactivity against nucleophilic attack. Reactivity of the male hormone $\mathbf{3}$ against nucleophilic attack should be significantly greater than that of female hormone 4. We saw above that the reactivity of $\mathbf{4}$ against electrophilic attack is greater than that of 3. The type of LUMO-1 of the majority of the

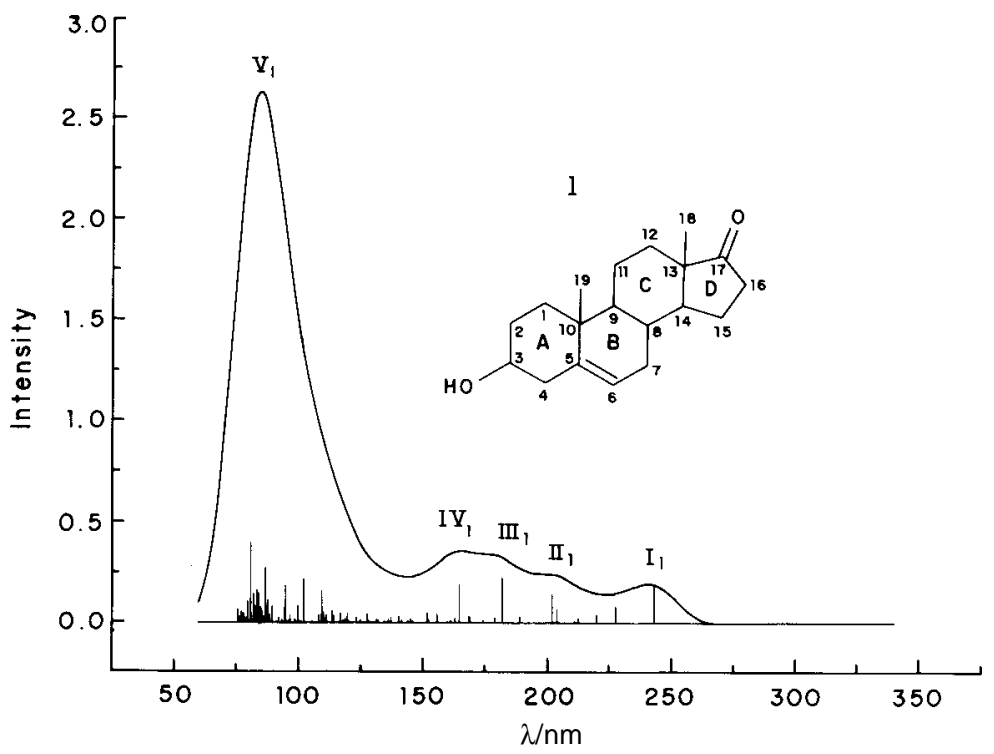

Figure 2. Simulated spectrum of dehydroepiandrosterone (1) constructed with the excitation energies and oscillator strengths calculated by the HAM/3 method.

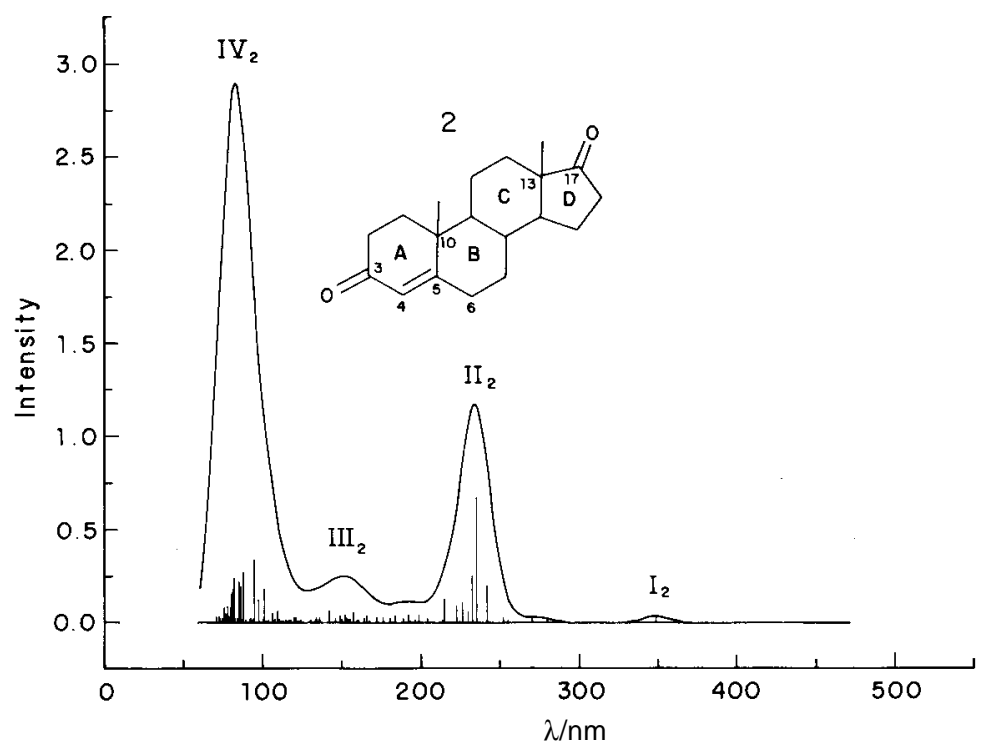

Figure 3. Simulated spectrum of androstenedione (2) constructed with the excitation energies and oscillator strengths calculated by the HAM/3 method. 
molecules in Table 2 is $\pi^{*}$ (pi antibonding) orbital of carbonyl $(\mathrm{C}=\mathrm{O})$. Only exception is the female hormone $\mathbf{4}$ in which the type of LUMO- 1 is $\pi^{*}$ (pi antibonding) orbital of its benzene ring.

Table 2. Electron affinities $(\mathrm{eV})$ that originate from some Lowest Unoccupied Molecular Orbitals (LUMOs) of the five steroids calculated with the HAM/3 method.

\begin{tabular}{|c|c|c|}
\hline Steroid & $\mathrm{HAM} / 3$ & Type of MOs \\
\hline 1 & $\begin{array}{l}+1.19 \\
+0.09 \\
-3.79 \\
-6.73\end{array}$ & $\begin{array}{l}\pi^{*}(\mathrm{C} 17=\mathrm{O}) ; \mathrm{LUMO}-1 \\
\pi^{*}(\mathrm{C} 5=\mathrm{C} 6) ; \text { LUMO-2 } \\
\text { LUMO-3 } \\
\text { LUMO-4 }\end{array}$ \\
\hline 2 & $\begin{array}{l}+2.32 \\
+1.22 \\
-1.83 \\
-6.73\end{array}$ & $\begin{array}{l}\pi^{*}(\mathrm{C} 3=\mathrm{O}) ; \text { LUMO-1 } \\
\pi^{*}(\mathrm{C} 17=\mathrm{O}) ; \text { LUMO-2 } \\
\pi^{*}(\mathrm{C} 4=\mathrm{C} 5) ; \text { LUMO-3 } \\
\text { LUMO-4 }\end{array}$ \\
\hline 3 & $\begin{array}{l}+2.37 \\
-1.78 \\
-3.99 \\
-6.77\end{array}$ & $\begin{array}{l}\pi^{*}(\mathrm{C} 3=\mathrm{O}) ; \mathrm{LUMO}-1 \\
\pi^{*}(\mathrm{C} 4=\mathrm{C} 5) ; \text { LUMO-2 } \\
\text { LUMO-3 } \\
\text { LUMO-4 }\end{array}$ \\
\hline 4 & $\begin{array}{l}+0.18 \\
-0.14 \\
-3.71 \\
-4.33 \\
-7.37\end{array}$ & $\begin{array}{l}\pi_{1} * \text { (benzene ring); LUMO-1 } \\
\pi_{2}{ }^{*} \text { (benzene ring); LUMO-2 } \\
\pi_{3} * \text { (benzene ring); LUMO-3 } \\
\text { LUMO-4 } \\
\text { LUMO-5 }\end{array}$ \\
\hline 5 & $\begin{array}{l}+2.19 \\
-1.92 \\
-4.10\end{array}$ & $\begin{array}{l}\pi^{*}(\mathrm{C} 3=\mathrm{O}) ; \text { LUMO-1 } \\
\pi^{*}(\mathrm{C} 4=\mathrm{C} 5) ; \text { LUMO-2 } \\
\text { LUMO-3 }\end{array}$ \\
\hline & -6.89 & LUMO-4 \\
\hline
\end{tabular}

$1 \mathrm{eV}=1.60 \times 10^{-19} \mathrm{~J}$

Using the calculated values of ionization energy (I) and electron affinity (A) in Tables 1 and 2, molecular hardness $(\eta \approx(I-A) / 2)$, and Mulliken's molecular electro-negativities $(\chi \approx(\mathrm{I}+\mathrm{A}) / 2))$ can be calculated (Table 3$)$. Molecular hardness and electronegativity can be considered as reactivity indices. The female hormone $\mathbf{4}$ is the hardest and its molecular electronegativity is the smallest among the five steroids. It has the least tendency of withdrawing electron from others. On the other hand, male hormone $\mathbf{3}$ is one of the least hard steroids and its electronegativity is the greatest among the molecules. It has the greatest tendency of withdrawing electron from others. In this way, the female and the male hormones show somewhat opposite trends. According to the HSAB literature ${ }^{19}$, high stability and low reactivity are associated with high hardness. The hardness increases in the order $\mathbf{2} \rightarrow \mathbf{3} \rightarrow \mathbf{4}$. Actual biotransformation proceeds also in the order $\mathbf{2} \rightarrow \mathbf{3} \rightarrow \mathbf{4}$. It seems that the biotransformation proceeds from soft molecule to hard molecule. Exception is the $\mathbf{1} \rightarrow \mathbf{2}$ transformation. The hardness of compound $\mathbf{1}$ is greater than that of compound $\mathbf{2}$, but actual biotransformation proceeds from $\mathbf{1} \rightarrow \mathbf{2}$. This indicates that we can not predict the direction of the biotransformation by just comparing molecular hardness of the molecules involved.

Table 3. Molecular hardness $(\eta \approx(I-A) / 2)$, and Mulliken's molecular electronegativities $(\chi \approx(\mathrm{I}+\mathrm{A}) / 2)$ of the five steroides, calculated using the ionization energies (I) and electron affinities (A) listed in Tables 1 and 2.

\begin{tabular}{lcc}
\hline Steroid & $\eta($ in $\mathrm{eV})$ & $\chi$ (in $\mathrm{eV})$ \\
\hline $\mathbf{1}$ & 3.94 & 5.13 \\
$\mathbf{2}$ & 3.20 & 5.52 \\
$\mathbf{3}$ & 3.22 & 5.59 \\
$\mathbf{4}$ & 4.03 & 4.21 \\
$\mathbf{5}$ & 3.28 & 5.47 \\
\hline $1 \mathrm{eV}=1.60 \times 10^{-19} \mathrm{~J}$ & &
\end{tabular}

$1 \mathrm{eV}=1.60 \times 10^{-19} \mathrm{~J}$.

The simulated spectra corresponding to excitation of electrons from ground to excited states of the five steroids in the region between $50 \mathrm{~nm}$ and $300 \mathrm{~nm}$ are shown in Figures 2-6. A glance at the five figures reveals immediately that there is a very strong, characteristic band in the region between $75 \mathrm{~nm}$ and $100 \mathrm{~nm}$ in all of the five spectra. The strong band is the consequence of overlap of many transitions, with significant oscillator strengths, densely packed below ca. $100 \mathrm{~nm}$. Transitions are of $\sigma^{*} \leftarrow \sigma$ type mainly concentrated on $\mathrm{B}$ and $\mathrm{C}$ rings of the steroid skeleton. The strong band in the region between $c a$. $75 \mathrm{~nm}$ and $c a$. $100 \mathrm{~nm}$ could be a fingerprint of steroid skeleton. On the other hand, the type of spectrum, band shape and intensity, above $c a .150 \mathrm{~nm}$ (low energy region) is different from molecule to molecule. We discuss the five spectra separately. The spectrum of $\mathbf{1}$ (Figure 2) in the low energy region consists of four poorly resolved peaks $\mathrm{I}_{1}, \mathrm{II}_{1}, \mathrm{III}_{1}$ and $\mathrm{IV}_{1}$. The suffix 1 of the band designation number (I, II,...) indicates that it is exhibited by compound 1 . The band designation number starts from the band located at the longest wave length side of the spectrum and increases towards the short wavelength side. Thus the first band, $\mathrm{I}_{1}$, is associated to the band at $243 \mathrm{~nm}$ (see Figure 2), which appears at the longest wavelength side of the spectrum, of the compound $\mathbf{1}$. The four peaks consist of four medium intensity transitions together with low intensity transitions nearby. The $\mathrm{I}_{1}$ band at $243 \mathrm{~nm}$ is due to transitions from inner molecular orbitals (MO's) to the first lowest unoccupied MO (LUMO-1). The main characteristic of LUMO- 1 is $\pi$ antibonding orbital of carbonyl at $\mathrm{C} 17, \pi^{*}$ (C17=O, see Table 2). The $\mathrm{II}_{1}, \mathrm{III}_{1}$ and $\mathrm{IV}_{1}$ bands are due to transitions from inner MO's to the second lowest unoccupied MO (LUMO-2). LUMO-2 consists mainly of $\pi *$ in $\mathrm{C} 5=\mathrm{C} 6$. There are three bands, $\mathrm{I}_{2}, \mathrm{II}_{2}, \mathrm{III}_{2}$, in the spectrum of molecule 2 (Figure 3 ) in the region between $150 \mathrm{~nm}$ and $400 \mathrm{~nm}$. The low intensity band $\mathrm{I}_{2}$ at $348 \mathrm{~nm}$ is 


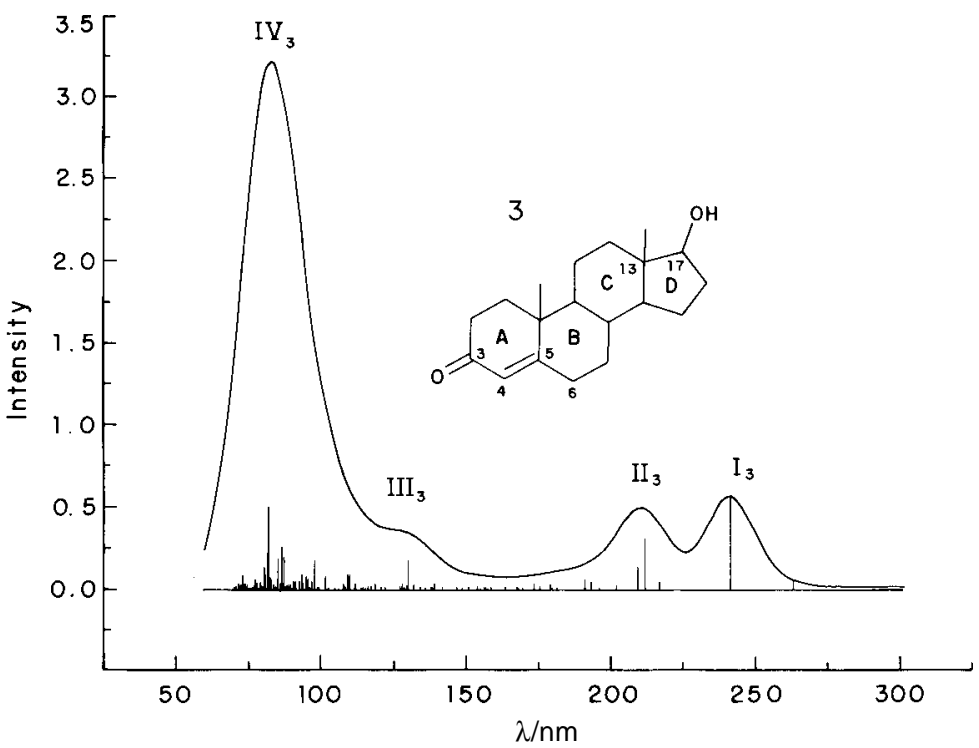

Figure 4. Simulated spectrum of testosterone (3) constructed with the excitation energies and oscillator strengths calculated by the HAM/3 method.

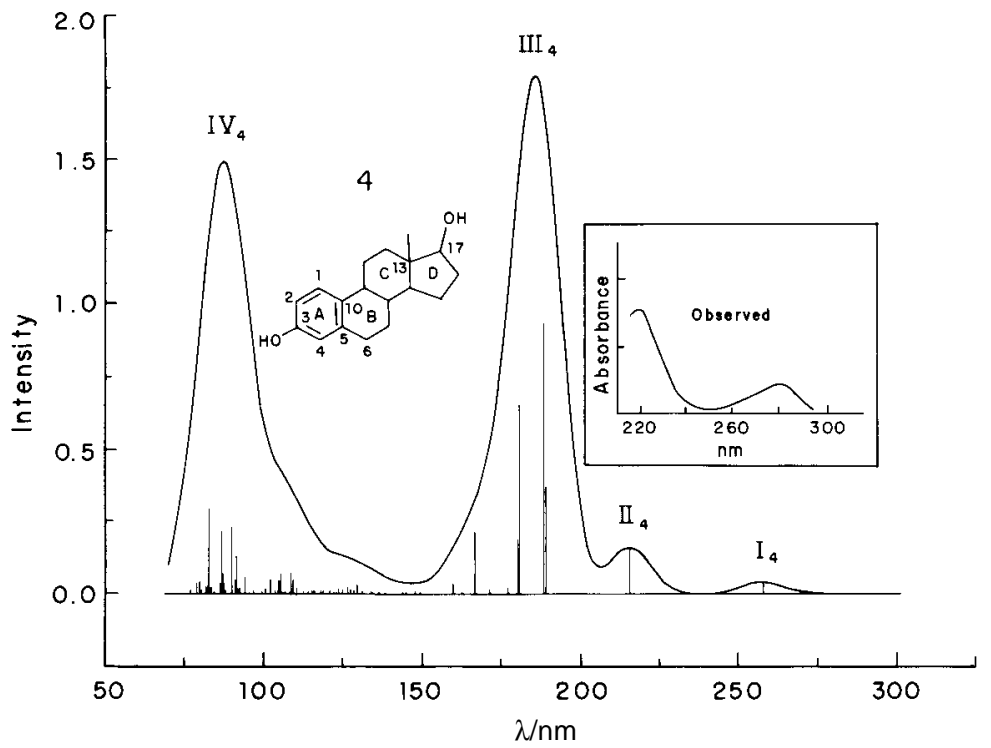

Figure 5. Simulated spectrum of estradiol-17b (4) constructed with the excitation energies and oscillator strengths calculated by the HAM/3 method. Observed spectrum between $220-300 \mathrm{~nm}$ in the inset.

mainly due to the $\pi *(\mathrm{C} 3=\mathrm{O}) \leftarrow \pi(\mathrm{C} 17=\mathrm{O})$ transition. The strong band, $\mathrm{II}_{2}$, around $235 \mathrm{~nm}$ is due to the overlap of several allowed transitions of $\pi^{*}(\mathrm{C} 3=\mathrm{O}) \leftarrow \pi(\mathrm{C} 4=\mathrm{C} 5)$ and $\pi^{*}(\mathrm{C} 17=\mathrm{O}) \leftarrow \pi(\mathrm{C} 4=\mathrm{C} 5)$ types. There are three peaks, $\mathrm{I}_{3}$, $\mathrm{II}_{3}$, and $\mathrm{III}_{3}$ in the region above $c a .100 \mathrm{~nm}$ in the spectrum of testosterone ( 3 ; Figure 4 ). The $\mathrm{I}_{3}$ peak is due mainly to the $\pi^{*}(\mathrm{C} 3=\mathrm{O}) \leftarrow \pi(\mathrm{C} 4=\mathrm{C} 5)$ transition. The $\mathrm{II}_{3}$ band in the vicinity of $212 \mathrm{~nm}$ is a composite of a few transitions from inner orbital to $\pi^{*}(\mathrm{C} 3=\mathrm{O})$. The $\mathrm{III}_{3}$ band is mainly due to transitions to $\pi^{*}(\mathrm{C} 4=\mathrm{C} 5)$ from inner orbitals. The spectrum of the female hormone 4 in the region between $c a .150 \mathrm{~nm}$ and $c a .300 \mathrm{~nm}$, in Figure 5, is substantially different from that of the male hormone (3, Figure 4$)$ in the corresponding region. There are three distinct bands, $\mathrm{I}_{4}, \mathrm{II}_{4}$, and $\mathrm{III}_{4}$ in the region. They all originate essentially from $\pi^{*} \leftarrow \pi$ transitions in the benzene ring of the steroid. The first low intensity band $\left(\mathrm{I}_{4}\right)$ at $c a$. $258 \mathrm{~nm}$ is due to the $\pi_{1}$ (LUMO1) $\leftarrow \pi_{1}(\mathrm{HOMO}-1)$ transition. The second band ( $\left.\mathrm{II}_{4}\right)$ at ca. $216 \mathrm{~nm}$ is mainly due to $\pi_{2} *$ (LUMO- 2$) \leftarrow \pi_{1}$ (HOMO1) transitions. An observed spectrum taken from the literature ${ }^{20}$ is schematically redrawn for the sake of comparison (inset in Figure 5). There are two observed peaks, at $c a .280 \mathrm{~nm}$ and at $c a .220 \mathrm{~nm}$. The corresponding simulated spectrum exibits peaks at $258 \mathrm{~nm}\left(\mathrm{I}_{4}\right)$ and at $216 \mathrm{~nm}\left(\mathrm{II}_{4}\right)$. The relative separation between the two peaks and band shape are similar between the observed and the 


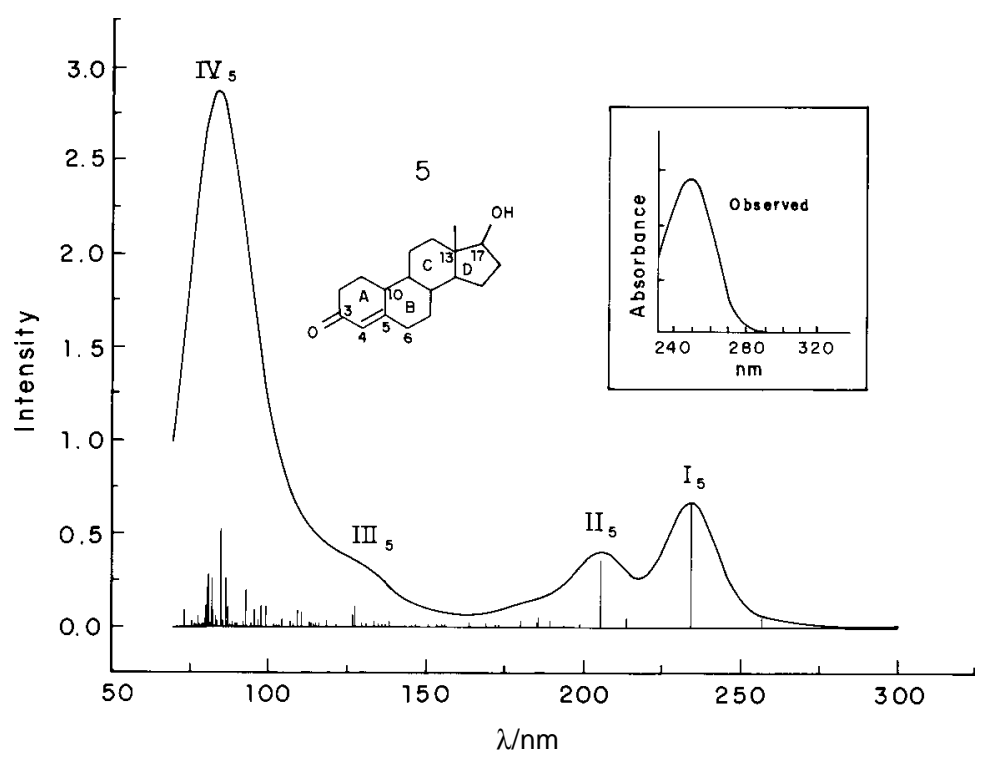

Figure 6. Simulated spectrum of nortestosterone (5) constructed with the excitation energies and oscillator strengths calculated by the HAM/3 method. Observed spectrum between $240-300 \mathrm{~nm}$ in the inset.

simulated spectrum. The $\mathrm{III}_{4}$ band is very strong and characteristic. It is a composite of some strong transitions originated from $\pi_{1} *$ (LUMO- $) \leftarrow \pi_{2}$ (HOMO-2); $\pi_{2} *$ (LUMO- 2$) \leftarrow \pi_{1}$ (HOMO- 1$) ; \pi_{2} *($ LUMO -2$) \leftarrow$ $\pi_{2}$ (HOMO-2) and other similar transitions all of which are of $\pi^{*} \leftarrow \pi$ type transitions in the benzene ring of the steroid. The simulated spectrum corresponding to excitation of electrons from the ground state to excited states of the steroid $\mathbf{5}$ is shown in Figure 6. Three distinguishable bands $\left(\mathrm{I}_{5}, \mathrm{II}_{5}, \mathrm{III}_{5}\right)$ can be seen in the $120 \mathrm{~nm}-300 \mathrm{~nm}$ region. The first band, $\mathrm{I}_{5}$, appears at $234 \mathrm{~nm}$. It corresponds to the $\pi^{*}(\mathrm{C} 3=\mathrm{O}) \leftarrow \pi(\mathrm{C} 4=\mathrm{C} 5)$ transition, where $\pi^{*}(\mathrm{C} 3=\mathrm{O})$ is the $\pi$ antibonding orbital of the carbonyl at the ring position 3 and $\pi(\mathrm{C} 4=\mathrm{C} 5)$ is the $\pi$ bonding orbital at the positions 4 and 5 of the steroid skeleton. The observed UV spectrum (in the $240 \mathrm{~nm}-300 \mathrm{~nm}$ region) of $\mathbf{5}$ in the literature ${ }^{20}$ is schematically redrawn in the inset of Figure 6 for the sake of comparison. There is a single broad band at $c a$. $245 \mathrm{~nm}$ in the observed spectrum. The calculated $\mathrm{I}_{5}$ band looks very similar to the observed band. We conclude that the observed band in the $240 \mathrm{~nm}-300 \mathrm{~nm}$ region corresponds to the calculated band $\mathrm{I}_{5}$ and that is due mainly to the $\pi^{*}(\mathrm{C} 3=\mathrm{O}) \leftarrow \pi(\mathrm{C} 4=\mathrm{C} 5)$ transition. The peak position of the observed band is located $c a .10 \mathrm{~nm}$ longer wavelength side, in comparison to the calculated band $\mathrm{I}_{5}$. This is most likely due to solvent effect in the observed band. In the theoretical calculation, transition energies of isolated molecules were calculated. Hence, solvent effect was not taken into account in the simulated spectrum. There is a low intensity band at $257 \mathrm{~nm}$, which is visible only as a short stick at the right hand side tail of the $\mathrm{I}_{5}$ band. In fact there are three additional very low intensity calculated transitions at 280, 291 and $428 \mathrm{~nm}$. The $428 \mathrm{~nm}$ transition corresponds to the $\pi^{*}(\mathrm{C} 3=\mathrm{O}) \leftarrow \eta(\mathrm{O} 3)$ transition. The $\mathrm{II}_{5}$ band at $205 \mathrm{~nm}$ is due to transitions mainly from orbital located in $\mathrm{C}$ and $\mathrm{D}$ rings to the $\pi^{*}(\mathrm{C} 3=\mathrm{O})$. The $\pi^{*}(\mathrm{C} 3=\mathrm{O})$ $\leftarrow \pi(\mathrm{C} 4=\mathrm{C} 5)$ transition also contributes to this band. The spectrum of steroid $\mathbf{3}$ in Figure 4 appears very much similar to the spectrum of steroid 5 in Figure 6. The molecular structure of the two steroids, $\mathbf{3}$ and $\mathbf{5}$, are very similar. The only difference is the presence, in $\mathbf{3}$, or absence, in $\mathbf{5}$, of a methyl group at position 10. Interpretation and assignment of each band of the spectrum of $\mathbf{3}$ is almost identical to that of $\mathbf{5}$.

It is hoped that the present theoretical studies aid understanding chemical and biological properties of the steroids and stimulate other new experimental works on the electronic spectra of the steroids.

\section{Acknowledgment}

We thank Dr. Yoshiyuki Hase for his technical aid on the use of the computer program SPECTRUM and for stimulating discussions. The authors thank CNPq-Conselho Nacional de Desenvolvimento Científico e Tecnológico for the research fellowships and CENAPAD-SP for the computer facilities.

\section{References}

1. Devlin, T. M.; Ed., Textbook of Biochemistry with Clinical Correlations, $4^{\text {th }}$ ed.,Willey-Liss, New York, 1997, p.895. 
2. Takahata, Y. and Vendrame, R. J. Mol. Struct. (THEOCHEM) 1997, 391, 169.

3. Åsbrink, L.; Fridh, C.; Lindholm, E. Chem. Phys. Lett. 1977, 52: 63; (b) ibid, 1977, 52, 69; (c) ibid, 1977, 52, 72.

4. Lindholm, E. and Asbrink, L. Molecular Orbitals and their Energies, Studied by the Semiempirical HAM Method, Spring-Verlag, Berline, 1985.

5. Åsbrink, L.; Fridh, C.; Lindholm, E. J. Electron Spectr. and Related Phenom. 1979, 16, 65.

6. Fridh, C.; Åsbrink, L.; Lindholm, E. Chem. Phys. 1979, 27, 169.

7. Åsbrink, L.; Fridh, C.; Lindholm, E.; Chong, D. P. Chem. Phys. 1979, $43,189$.

8. Takahata, Y. An. Acad. Brasil. Ciência. 1985, 57, 39.

9. Takahata, Y. J. Molec. Struct. (THEOCHEM). 1993, 283, 289.

10. Takahata, Y.; Hara, T.; Narita, S.; and Shibuya, T. J. Mol. Struct. (THEOCHEM). 1998, 431, 219.

11. Takahata, Y. J. Mol. Struct. (THEOCHEM). 1995, 335, 229.

12. Åsbrink, L.; Fridh, C.; Lindholm, E. HAM/3: Molecular Orbital Calculations by the HAM/3 Method. QCPE. 1980, No. 393.
13. Soper, P. D.; Copyright 1997 E. I. du Pont de Nemours and Company.

14. Cvitas, T.; Kovac, B.; Pasa-Tolic, Lj.; Ruscic, B.; Klasinc, L.; Knop, J. V.; Bhacca, N. S. and McGlynn, S. P. Pure Appl. Chem. 1989, 61, 2139.

15. Fukui, K.; In: Hanfner, K.; Lehn, J-M.; Rees, C. W.; Schlever, Pv. R.; Trost, B. M.; Zahradnik, R. (eds), Reactivity and Structure Concept in Organic Chemistry, Spring-Verlag, Berlin. 1975, p.34.

16. Duax, W. L.; Griffin, J. F. and Weeks, C. M. in : Interaction of Steroid Hormone Receptors with DNA, ed. Sluyser M.,(Ellis Horwood Ltd., Chichester, England , 1985) p.83.

17. Tanenbaum, D. M. ; Wang, Y.; Williams, S. P. and Sigler, P. B. (1998); Proc. Natl. Acad. Sci. USA, 1998, 95,5998.

18. Anstead, G. M.; Carlson, K. E.; Katzenellenborgen J. Á. Steroids, 1997, 62, 268.

19. Pearson, R. G.; Hard and Soft Acids and Bases, Dowden, Hutchinson and Ross, Stroudenburg, Pa. 1973.

20. Zhao, Q.; Mildvan, A. S. and Talalay, P. Biochemistry, 1995, 34, 426.

Received: June 16, 2000

Published on the web: February 15, 2001

FAPESP helped in meeting the publication costs of this article. 